\title{
Study of influence of the alkaline component on the physico-mechanical properties of the low clinker and clinkerless waterproof compositions
}

\author{
Yuliya Savchuk*, Andrii Plugin, Vitalii Lyuty, Oleksii Pluhin, and Olga Borziak \\ Ukrainian State University of Railway Transport, Feuerbach sq. 7, 61050 Kharkiv, Ukraine
}

\begin{abstract}
The influence of the alkaline component on the physicomechanical properties and the structure of the clinkerless waterproof composition on the basis of Kryvyi Rih blast furnace slag and an alkaline component - sodium hydroxide - have been investigated. High and very high correlation between the compressive strength $f$ of the composition and the alkali - sodium hydroxide - strength $A / S$ has been established. The dependence $f$ on $A / S$ has an extreme wave-like pattern with maxima at $A / S=1.5 \%$ and $15-20 \%$, which is explained by the formation of one and two series of hydration products between slag particles similarly to Portland cement-based compositions. It has been established that the hydration products of the composition are predominantly gel-like one, such as hydrosilicate gel and zeolite-like sodium calcium hydroalumosilicates; fewer crystalline hydration products include prismatic and needle-like crystals of complex salts of aluminate phases. The pore size in the composition structure mostly does not exceed 2 microns, although single pores up to 10 microns in size also occur.
\end{abstract}

\section{Introduction}

During the operation, concrete structures of engineering installations suffer damage not only from mechanical loads, but also temperature and humid influences and deformations, the impact of aggressive media, electrical influences - leakage currents and wandering currents, electrical potentials and charges, etc. This requires their repair and protection against aggressive action of chemically and biologically active media, electrical currents, potentials and charges. Cement mortars, dry mixtures, Portland cement clinker-based plasters are mainly used for repair and protection [1-3]. An effective variety of such materials is the Portland cement-based penetrating compositions which compact the surface concrete layers of the damaged installation [4, 5]. However, Portland cement-based materials are often insufficiently stable in many operating conditions. For example, at metallurgical plants, they are quickly broken when affected by acid gases, such as sulphur dioxide, carbon dioxide (Fig. 1) [6,7]. In such conditions, alkaline and slag-alkali binding materials produced from blast-furnace granulated slag and characterized by high corrosion resistance in many environments are more resistant $[8,9]$. Therefore, the development of

* Corresponding author:uliasavhyk83@gmail.com 
penetrating compositions based on slag-alkali binding materials that would be resistant to acid gases and could be made from available raw materials is a relevant task. The creation of such compositions will also contribute to solving the environmental and economic problems of industrial waste utilization.

a)

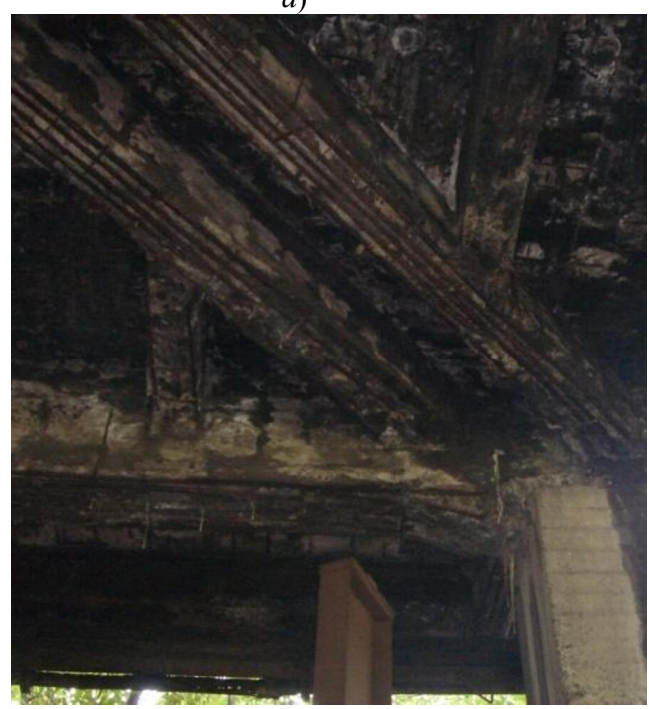

b)

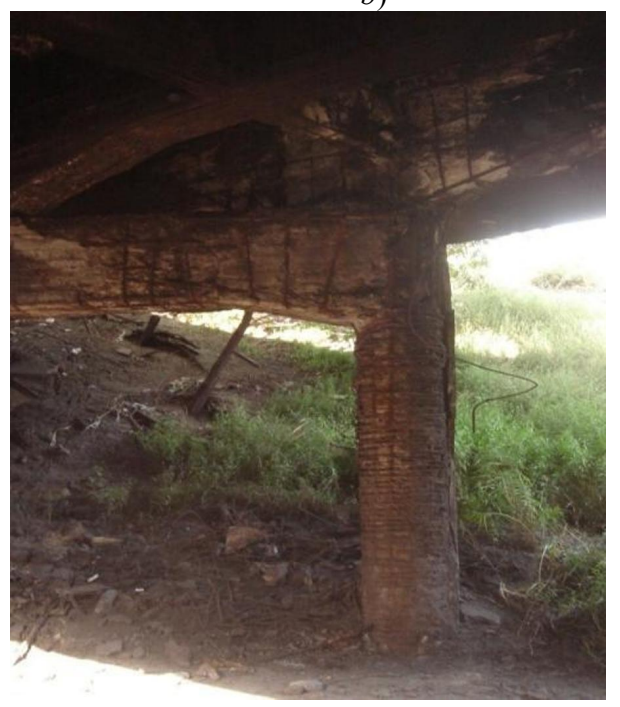

Fig. 1. Damage of reinforced concrete girders $(a, b)$ and supports $(b)$ of the pipeline within the territory of PJSC MMK Azovstal (Mariupol) in the area with high content of sulphur dioxide and carbon dioxide in the air.

Penetrating action, adhesion to the repaired surface, protective properties and water resistance of the penetrating compositions depend on their structure $[1,2,10,11]$ and are achieved by adding chemical [4] and mineral admixtures [2, 12-15], disperse reinforcement [16-19]. A complex of such additives, including nitrates, carbonates, sulphates, sodium and calcium chlorides, are proposed in $[4,16,18]$, but the effect of this complex additive has been tested only for Portland cement and its varieties.

The authors investigate the effect of the complex chemical additive and the alkaline component on the physico-mechanical properties of artificial stone on the basis of a slagalkali binding material [6, 7]. It has been established in [7], that its physic-mechanical properties in the investigated range are unaffected by the content of the complex chemical additive, but are extremely dependent on the content of sodium hydroxide. The maximum compressive and bending strengths have been recorded when the content of sodium hydroxide was about $5 \%$ of the slag content by weight, but the study was conducted only on the slag of one metallurgical plant - PJSC MMK Azovstal (Mariupol), and the region of the low content of sodium hydroxide less than $1 \%$ remained unexplored.

The purpose of the work is determination of the influence of the alkaline component on the physic-mechanical parameters and the structure of the slag-alkali composition intended for use as a penetrating waterproof compound.

Tasks of the study: investigation of the dependences of compressive strength of a slagbased composition on the content of sodium hydroxide; conducting electron microscopic studies of the structural features of the solidified composition 


\section{Research methods and materials}

The quartz sand composition with a grain fineness 1.1, blast-furnace granulated slag of PJSC MMK Azovstal (Mariupol), OJSC Mittal Steel Kryviy Rih (Kryvyi Rih), ground so that at least $85 \%$ pass through a 008 sieve, sodium hydroxide $\mathrm{NaOH}$ was investigated. A complex chemical additive that provides penetrating action and water resistance of the composition contained nitrates, carbonates, sulphates, sodium and calcium chlorides in the ratio established in $[4,16,18]$. A dry mixture was prepared from all components, which was mixed with water immediately before use. Dependence of average consistency, water absorption, bending and compressive strength, water resistance (softening factor) of the composition on the content of sodium hydroxide and the complex chemical additive was studied. The relationship between them was estimated by the coefficient of correlation by the Chaddock scale.

For the study, mixtures with different ratios of components were prepared. The ratio in the base composition was: sand - $60 \%$, slag - $35 \%$, sodium hydroxide - $5 \%$ by weight. The amount of the complex chemical additive was $1 \%$ of the slag weight. The amount of sodium hydroxide varied from 0 to $40 \%$ by slag weight. The amounts of sodium hydroxide and the complex chemical additive were increased, while the sand to slag ratio 60:35 remained unchanged. For the determination of bending and compressive strength and average consistency, water absorption, water resistance (softening factor), samples shaped as small beams $40 \times 10 \times 10 \mathrm{~mm}$ in size were made from the mixture, which were tested by standard (conventional) methods after a fixed natural cure period. The softening factor was determined as the ratio of the compressive strength of the sample in the water-saturated to a constant mass state to the compressive strength in the air-dry state.

Electron microscopic analysis of the artificial stone structure was conducted at its spalls at $15 \mathrm{kV}$ using a scanning electron microscope Philips XL 30 ESEM-FEG by F.A.FingerInstitut für Baustoffkunde of Bauhaus-Universität Weimar.

\section{Results of experimental studies}

The dependences of the compressive strength $f$ of the Kryvyi Rih slag-based composition on the alkali - sodium hydroxide - strength $A / S$ are shown in Fig. 2, 3. Electronic microscopic images of artificial stone on Mariupol slag containing 5\% sodium hydroxide and a complex chemical additive of $1.5 \%$ of the slag weight are shown in Fig. 4.

\section{Discussion of results obtained in the study}

The analysis of Figs. 2 and 3 showed high and very high Chaddock correlation between the compressive strength of the composition and the content of sodium hydroxide - the squared correlation $R^{2}$ reaches $0.62-0.92$, the correlation coefficient $\mathrm{R}$ is $0.79-0.96$. The dependence of strength $f$ on the content of alkali - sodium hydroxide $-A / S$ for the Kryviy Rih slagbased composition, as well as for the Mariupol slag-based composition [7] has an extreme character, but unlike it - wave-like with maxima at $A / S=0.015(1.5 \%)$ and $0.15-0.20$ $(20 \%)$. This can be explained by the formation of one and two series of hydration products between slag particles and/or slag particles between sand grains similarly to cement concrete and compositions [19]. Evidently, for practical purposes, a dosage of alkali sodium hydroxide - should be $1.5 \%$. The obtained strength values are not very high - up to $10 \mathrm{MPa}$, which can be explained by the features of slag selection for the study and the method of determination. However, such values are quite sufficient for repair and 
protective plasters, since, as known, the strength and modulus of elasticity of the plaster must be less than those of the material of the repaired surface.

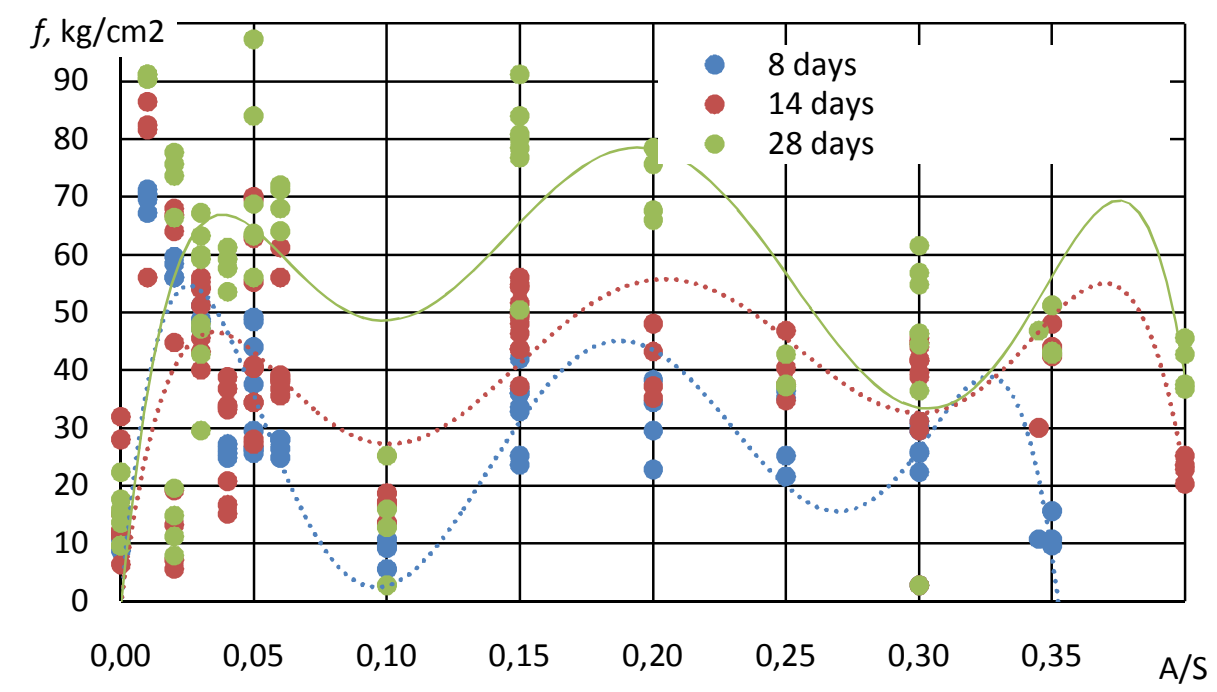

Fig. 2. Dependence of compressive strength $f$ of the Kryviy Rih slag-based composition on the content of alkaline $\mathrm{NaOH} A / S$ after 8,14 and 28 days of natural curing.

On the basis of the analysis of electron microscopic images shown in Fig. 4 and others is was established as follows. Fig. 4, $a$ shows a fraction of sand (right) and slag particles (left) covered with hydration products. The hydration products are mostly gel-like (Fig. 4, $b-d)$, probably, hydrosilic gel and zeolite-like sodium-calcium hydroaluminosilicates. Fewer crystalline hydration products are also observed - prismatic and needle-like crystals up to $2 \mu \mathrm{m}$ in length (Fig. 4, $a, c, d$ ), probably, complex salts of aluminate $A F m$ and $A f t$ phases [20-23]. No hexagonal plates of Portlandite are observed, which may be the evidence of a general deficit of crystalline hydration products and electroheterogeneous contacts and, as a result, low strength. Most pores are up to 2 microns in size between the hydration products (Fig. 4, d), the largest pore size is up to 10 microns (a single pore in the contact zone of sand grain, Fig. 4, $a$ ).

\section{Conclusions}

As a result of the research carried out:

1. High and very high correlation between the compressive strength $f$ of the Kryviy Rih slag-based composition and the alkali - sodium hydroxide - strength $A / S$ has been established with the correlation coefficient of 0.79-0.96. Dependence of $f$ on $A / S$ has an extreme wave-like character with maxima at $A / S=0.015(1.5 \%)$ and $0.15-0.20(20 \%)$. This is explained by the formation of one and two series of hydration products between the slag particles similarly to Portland cement-based compositions.

2. Hydration products of the composition are predominantly gel-like, apparently, hydrosilicidal gel and zeolite-like sodium calcium hydroaluminosilicates, fewer crystalline hydration products include prismatic and needle-like crystals of complex salts of aluminate phases. 
3. Physicochemical studies of the composition of the hydration products of the composition should be conducted in order to confirm the results of electron microscopic studies.

a)

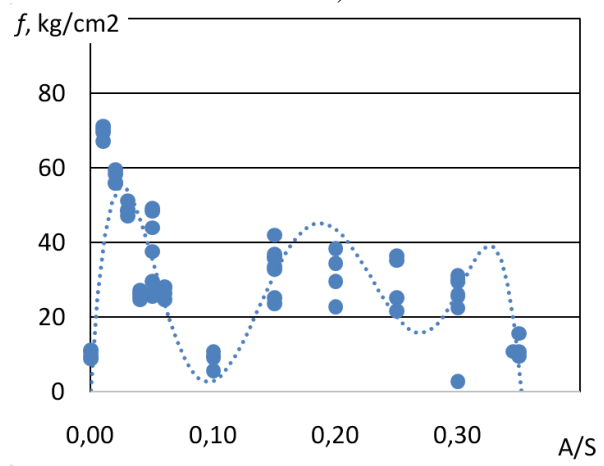

c)

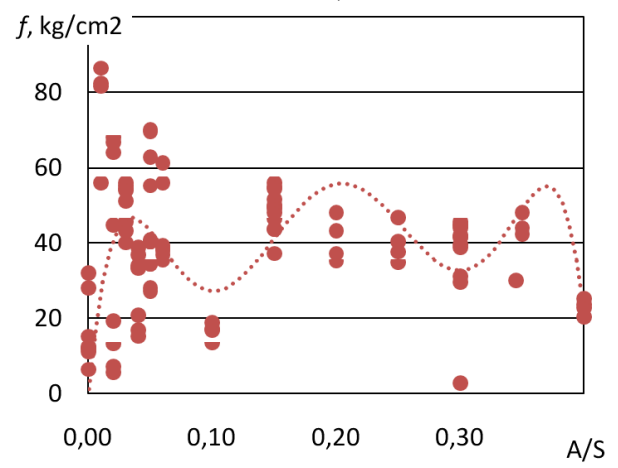

e)

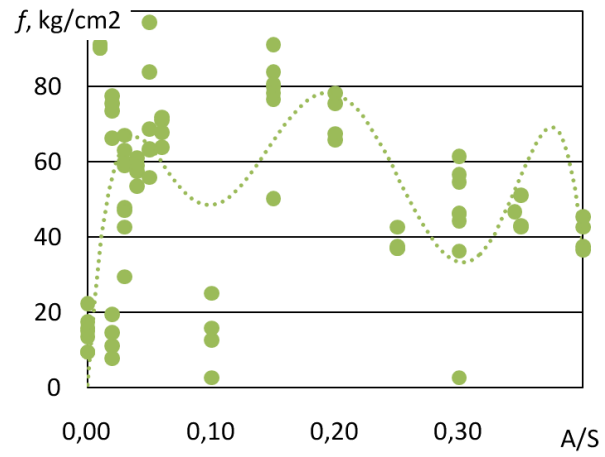

b)
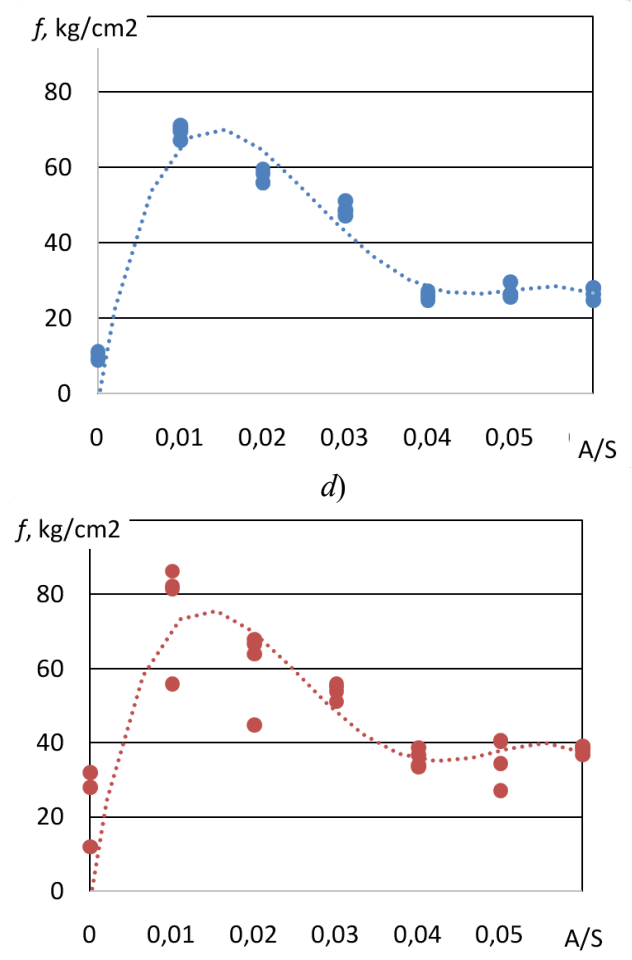

f)

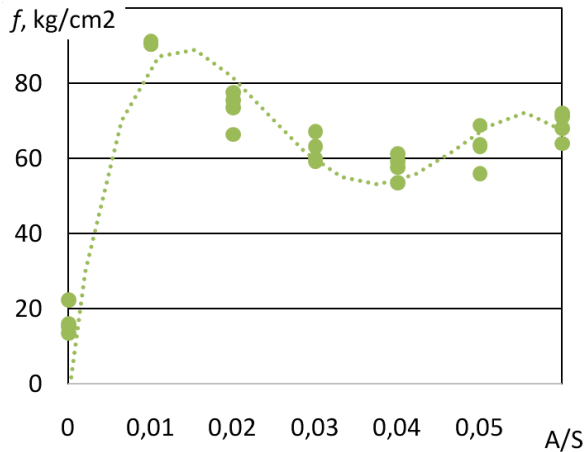

Fig. 3. Dependence of compressive strength $f$ of the composition on the content of alkaline $\mathrm{NaOH} \mathrm{A/S}$ after $8(\mathrm{a}, \mathrm{b}), 14$ (c, d) and 28 (e, f) days of natural curing: a, c, e - at $A / S$ range from 0 to 0.4 ; b, d, e at $A / S$ range from 0 to 0.06 . 
a)

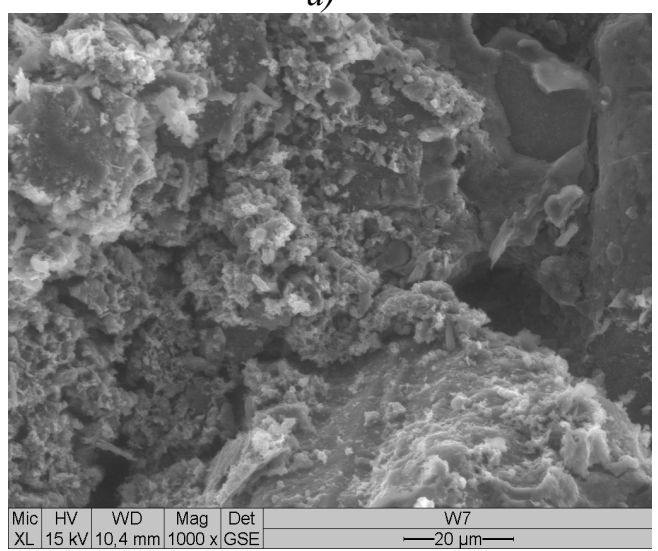

c)

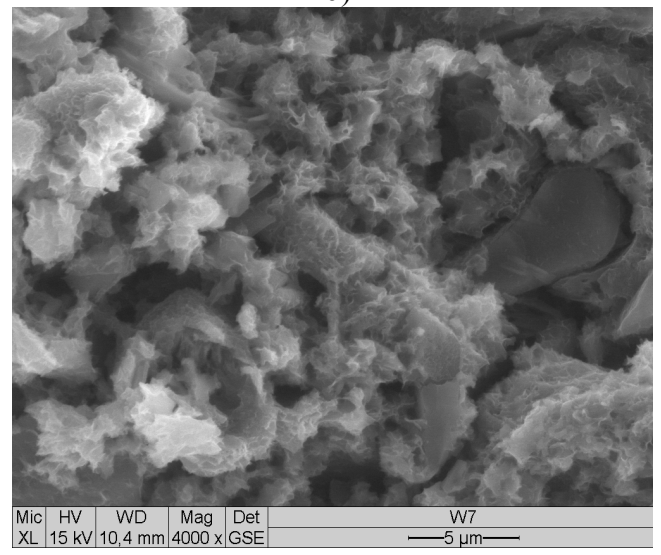

b)

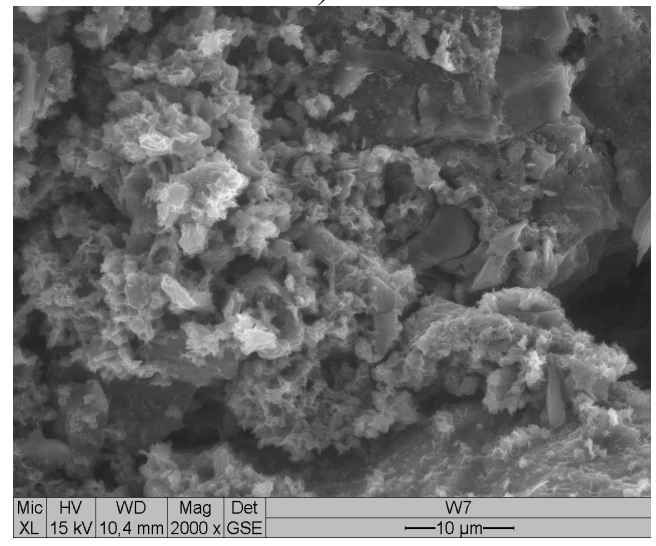

d)

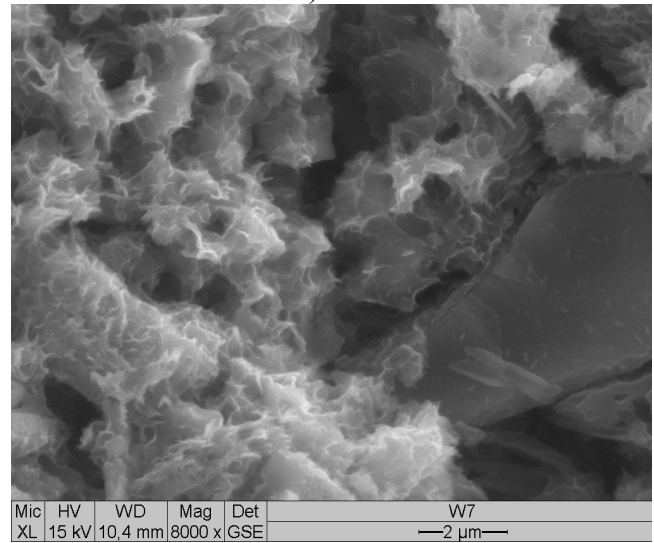

Fig. 4. Zoomed electron microscopic pictures of the composition: $\mathrm{a}-\times 1000 ; \mathrm{b}-\times 2000$; $-\times 4000$; $\mathrm{d}-\times 8000$. Each subsequent picture is a zoomed fragment of the previous one.

\section{References}

1 M. Sanytsky, T. Kropyvnytska, R. Kotiv, Advanced Materials Research, 923, 42-47 (2014)

2 O. Pluhin, A. Plugin, D. Plugin, O. Borziak, O. Dudin, Matec Web of Conference, 116, 01013 (2017)

3 P. V. Krivenko, M. Sanytsky, T. Kropyvnytska, R. Kotiv, Advanced Materials Research, 897, 45-48 (2014)

4 O.I. Demina, A.A. Plugin, E.B. Dedenyova, D.O. Bondarenko, T.A. Kostuk, A.I. Bondarenko, Functional Materials, 24 (3), 415-419 (2017)

5 D.O. Bondarenko, R.A. Yakovleva, T.O. Kostiuk, O.Yu. Proshin, 30th SAMPE Europe International Jubilee Conference, 563-569 (Paris, 2009)

6 A.A. Plugin, V.A. Liutyi, Yu.Iu. Savchuk, Zb. nauk. prats UkrDUZT, 171, 19-29 (2017)

7 A.A. Plugin, Y.Y. Savchuk, V.A. Liutyi, T.O. Kostiuk, D.O. Bondarenko Penetrating Fine-Clinker and Clinkerless Cement-Based Waterproof Compounds (19'Ibausil, Weimar, 2018) 
8 P.V. Kryvenko, E.K. Pushkareva Dolhovechnost shlakoshchelochnoho betona [Durability slag-alkali cement] (Kyiv, Budivelnyk, 1993)

9 Pavel V. Krivenko, Myroslav Sanytsky, Tetiana Kropyvnytska, Key Engineering Materials, 761, 193-196 (2018)

10 E. Lutskin, E. Shinkevich, Technical Journal, 9 (1-2015), 27-33 (2015)

11 E. Shinkevich, Y. Zaytsev, E. Lutskin, G. Bondarenko, A. Tymnyak, Proceeding of 2nd International conference on Microstructural-related Durability of Cementitious Composites, 1462-1468 (RILEM Publications SARL, 2017)

12 U. Marushchak, M. Sanytsky, T. Mazurak, Y. Olevych, Eastern-European Journal of Enterprise Technologies, 6/6 (84), 50-57 (2016)

13 O. Borziak, S. Vandolovskyi, V. Chajka, V. Perestiuk, O. Romanenko, Matec Web of Conference, 116, 01001 (2017)

14 M.H. Salyia, T.A. Kostiuk, Yu.A. Spyryn, A.A. Plugin, Zb. nauk. prats UkrDAZT, 130, 49-56 (2012)

15 U. Maruchchak, M. Sanytsky, S. Korolko, Y. Shabatura, N. Sydor, Eastern-European Journal of Enterprise Technologies, 2/6 (92), 34-41 (2018)

16 A.A. Plugin, T.O. Kostiuk, O.A. Plugin,D.O. Bondarenko, Yu.A. Sukhanova, N.N. Partala, International Journal of Engineering Research in Africa, 31, 59-68 (2017)

17 A.A. Plugin, T.A. Kostiuk, D.A. Bondarenko, M.H. Salyia, Naukovyi visnyk budivnytstva, 59, 157-162 (2010)

18 T.A. Kostiuk, A.A. Plugin, Al.A. Plugin, Zb. nauk. prats UkrDAZT, 148(2), 32-38 (2014)

19 A.N. Plugin, A.A. Plugin et al. Osnovy teorii tverdeniya, prochnosti, razrusheniya $i$ dolgovechnosti portlandtsementa, betona i konstruktsiy iz nikh (Naukova dumka, Kyiv, 2012)

20 T. Matschei, B. Lothenbach, F.P. Glasser, Cem. Concr. Res, 37 (2), 118-130 (2007)

21 M. Balonis, B. Lothenbach, G. Le Saout, F.P. Glasser, Cem. Concr. Res., 40(7), 10091022 (2010)

22 Balonis M., Medala M., Glasser F.P. Cem. Res. 23(3) (2011)

23 A.A. Plugin, R.F. Runova, International Journal of Engineering Research in Africa, 36, 69-73 (2018) 